\section{OPEN \\ JOURNAL \\ SYSTEMS}

ISSN:2237-2202
Available on line at Directory of Open Access Journals

Journal of Hyperspectral Remote Sensing v.7, n.5 (2017) 258-271

www.periodicos.ufpe.br/revistas/jhrs
Journal of

Hyperspectral

Remote Sensing

\title{
Sensitivity analysis and regionalization of reference evapotranspiration for the Amazon region
}

\author{
Helder J. F. da Silva ${ }^{*}$, Weber A. Gonçalves ${ }^{* *}$, Bergson G. Bezerra ${ }^{* *}$. \\ "PhD student at the Federal University of Rio Grande do Norte - UFRN, Post-Graduation Program in Climate Sciences - \\ PPGCC, Natal, RN, Brazil. E-mail: helderlagoia@gmail.com (Corresponding author) \\ "Teachers of the Federal University of Rio Grande do Norte - UFRN, PPGCC, Natal, RN, Brazil.
}

Received 14 September 2017; accepted 20 October 2017

\begin{abstract}
Sensitivity Analysis (SA) is important to understand the relative importance of climate variables in the reference evapotranspiration (ETo) computation. In this study, a sensitivity coefficient was used to predict ETo responses to disturbances of five climatic variables in the Amazonian Hydrographic Region - AHR (Brazilian Amazon). The ETo was estimated using the standardized equation of Penman-Monteith-FAO (PM-FAO). A 15-year meteorological data set of 38 surface meteorological stations were used in the study. An additional analysis was also presented to determine homogeneous regions of ETo by means of Cluster Analysis. The results showed that seven homogeneous sub-regions are sufficient to divide the AHR into different ETo patterns which were separated considering the intensity and the seasonal pattern of ETo. By the SA, the variables that contribute most to the computation of ETo using the PM-FAO method were the balance of radiation (Rn) and wind speed (u2). These results demonstrate that, in general, it should be emphasized to precise measures of insolation, since the precise estimation of $\mathrm{Rn}$ is directly associated with the measurement of this variable as well as of $\mathrm{u} 2$, which proved to be the second most influential variable in the ETo computation.

Keywords: Penman-Monteith, cluster analysis, sensitivity coefficient.
\end{abstract}

\section{Introduction}

Evapotranspiration (ET) is a key process in the hydrological cycle and undoubtedly the most complex component to determine, especially in tropical areas, where a large proportion of rain is returned to the atmosphere via ET, making it a major source of water vapor to our planet. It is estimated that ET is $60 \%$ of global precipitation and can reach almost $100 \%$ of rainfall in arid regions (Jovanovic and Israel, 2012). In addition, ET varies depending on landscape heterogeneity and topography, climate, vegetation type and soil properties (Mu et al., 2007). This makes the ET process very dynamic over time and variable in space. Therefore, understanding how this parameter varies in space and time is of paramount importance for understanding one of the critical components of the hydrological cycle.

Evapotranspiration of a reference surface, with well-developed vegetation under certain climatic conditions and unlimited water availability, is called potential evapotranspiration (ETp). In real conditions, however, water availability may be limited and the amount of effectively evapotranspirators water is less, being called real evapotranspiration (ETr) (Allen et al., 1998). In 1990, however, the United Nations Food and Agriculture Organization (FAO) convened a meeting of experts in the field in Rome to meet a number of objectives, including analysis of the concepts and procedures of the methodologies for calculating ET ( Allen et al., 1998; Carvalho et al., 2011). Thus, the new concept proposed for ETp has, in fact, become the Reference Evapotranspiration (ETo), which has been widely used to quantify the ET of a surface under standard conditions) or ideal, as an assumed cultivation height of $0.12 \mathrm{~m}$, a fixed surface force of $70 \mathrm{~s} \mathrm{~m}^{-1}$ and an albedo of 0.23 . Carvalho et al. (2011) point out that, in this case, the reference crop used is a hypothetical crop, whose characteristics closely resemble ET of grass.

Numerous methods have been introduced to compute ETo, causing conflict between producers, consultants and policy makers, making it difficult to choose the appropriate method for estimating ETo. In this regard, FAO recommended the use of the 
Penman-Monteith (PM) method, as this method was standardized by FAO Document No. 56 (Allen et al., 1998), to quantify ETo. Recent studies have concluded that the standardized Penman-MonteithFAO method (henceforth, FAO-FAO) provides a reliable and consistent basis for objectively assessing the relative performance of ETo equations in a variety of climates (Itenfisu et al., 2003; Gavilán et al., 2007).

Sensitivity Analysis (SA) plays an important role in model development, calibration, uncertainty analysis, scenario analysis and thus decision making (Yang, 2011). Sensitivity indices are very important for environmental modeling, especially for distributed models such as PM-FAO because of their high nonlinearity, non-monotonicity, highly correlated parameters and intensive computational requirements (Irmak et al., 2006; Yang, 2011;).

Pioneering research by Saxton (1975) and Beven (1979) and others have demonstrated the importance of SA in understanding the structure, the effect of variations in meteorological factors on evapotranspiration evaporation rates, and the effects of meteorological measurement errors, such as example by differentiating the aerodynamic terms for the Penman (1948) method with respect to each variable. Thus, SA investigates the effect of changing from one factor to another and also identifies the most sensitive parameters, which ultimately determines the set of parameters to be used in the subsequent calibration process (Irmak et al., 2006).

In the literature, SA techniques have been categorized in a number of ways (eg Frey and Patil, 2002; Saltelli et al., 2004, 2008; Yang, 2011). Some methods use a percentage variation in input and respond to the corresponding change in the output variables. Some other methods use an increase or decrease to a certain extent and record the observed changes (Kannan et al., 2007). A more efficient approach is to differentiate mathematically the equation or model under study (Gong et al., 2006; Silva et al., 2011; Ambas and Baltas, 2012; Paparizos et al., 2016).

Studies on the regional and seasonal behavior of PM-FAO sensitivity to meteorological variables are rare in the literature. Irmak et al. (2006) studied the sensitivity of the standard PM-FAO equation in different regions of the United States from semi-arid conditions to humid conditions. Gong et al. (2006) conducted a sensitivity study in the Yangtze River basin in China, calculating non-dimensional relative sensitivity coefficients to predict ETo responses to climate variable disturbances. In Brazil, these studies have been concentrated in the northeast and centralwest regions, probably due to the availability of data (Lemos Filho et al., 2010; Silva et al., 2011; Alencar et al., 2012).

The sensitivity of the PM-FAO equation has not yet been studied in the Amazon region, which due to its great territorial extension has different meteorological and climatic characteristics associated with topographic effects and the presence of meteorological systems that act at different time scales (Santos et al., 2015). Therefore, it is believed that a more comprehensive study on AS is necessary in this region, and due to its great territorial extension, to divide the Brazilian Amazon into homogeneous regions of evapotranspiration in order to contribute to these analyses.

In view of the above, the present study was carried out with the aim of: (1) Verifying how many sub regions are sufficient to represent homogeneous regions of ETo in the Brazilian Amazon; (2) To assess the sensitivity of the standardized PM-FAO equation to the climatic variables in the sub regions of the Brazilian Amazon, obtaining seasonal sensitivity coefficients and (3) to verify if there are significant differences between the homogeneous sub regions through the Analysis of Variance (ANOVA). Thus, quantitative estimation of the effect of different meteorological variables on ETo is also an important step in the study of the impact of climate change on ET and water balance components.

\section{Material and Methods}

\subsection{Study area}

The study area comprises the Amazon Hydrographic Region - RHA, which according to ANA (2016) is inserted in the Amazon basin, but is limited to the Brazilian territory (Figure 1). It has an approximate area of a total of $3,870,000 \mathrm{~km}^{2}$ (42\% of the national territory). The population in the RHA in 2010 was $9,694.728$ inhabitants $(5.1 \%$ of the country's population) and the demographic density of only 2.51 inhabitants per $\mathrm{km}^{2}$ (IBGE, 2010). The RHA is divided into 29 hydrographic units and covers 313 municipalities in seven states (Acre, Amazonas, Rondônia, Roraima, Amapá, Pará and Mato Grosso). It is characterized by an extensive 


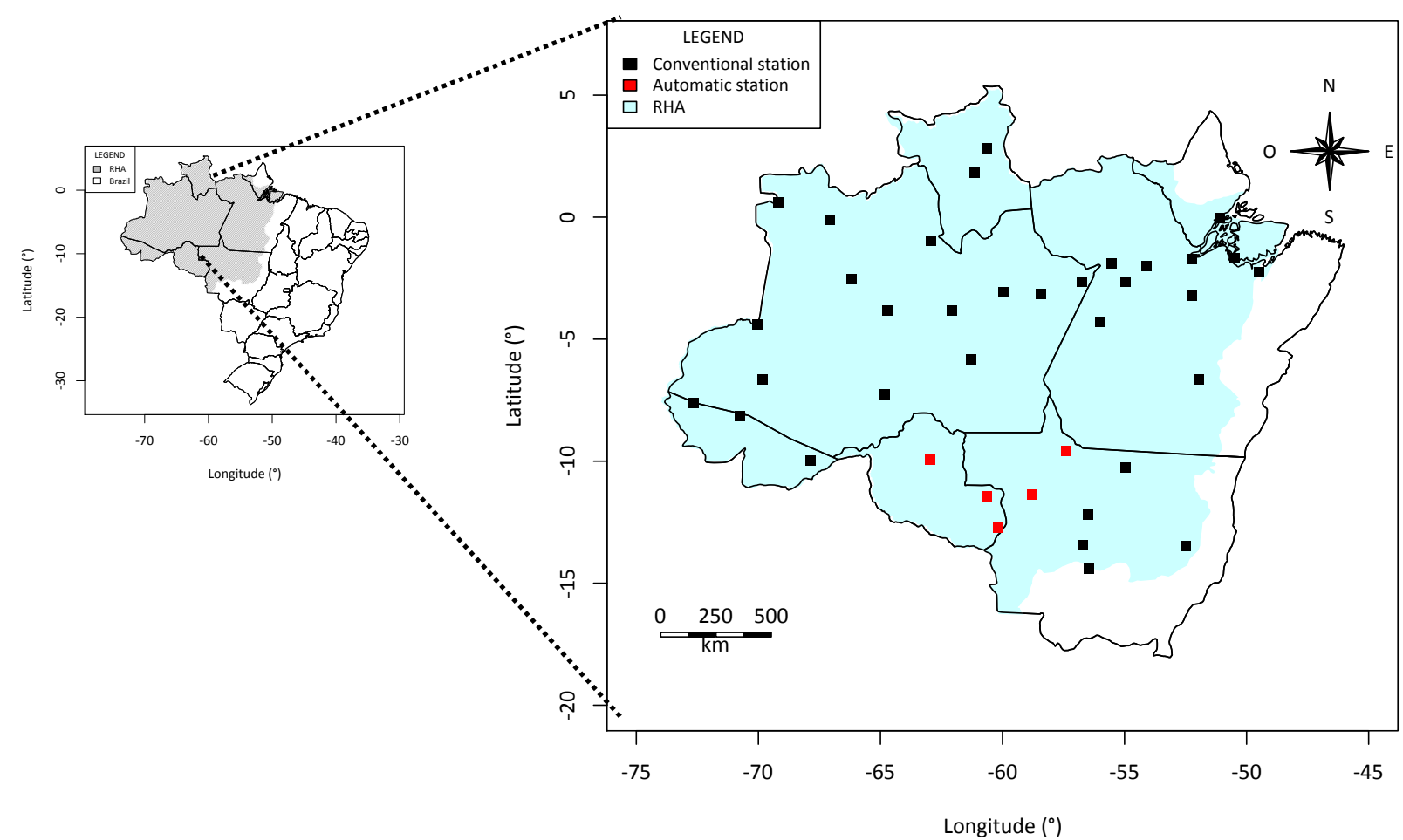

Figure 1 - Amazonian Hydrographic Region (Region of study) and spatial distribution of INMET's 38 surface meteorological stations.

According to Marengo and Nobre (2009), the average annual rainfall in the Amazon region is about $2,205 \mathrm{~mm} /$ year, ranging between 2,033 and 2,512 $\mathrm{mm}$. The surface water availability is $73,748 \mathrm{~m} 3 / \mathrm{s}$, which corresponds to $81 \%$ of the country's surface availability $\left(91,071 \mathrm{~m}^{3} / \mathrm{s}\right)$. The annual average temperature is in the range between 24 and $26{ }^{\circ} \mathrm{C}$. The hottest months are September and October, while the coldest months can range from June to August. The average annual evapotranspiration is $1,320 \mathrm{~mm}$ year ${ }^{-1}$, varying between 441 and 1,667 $\mathrm{mm}_{\text {year }}{ }^{-1}$.

\subsection{Weather data}

The monthly meteorological data (Table 1) required for the calculation of ETo by means of Equation (3) were extracted from the National Institute of Meteorology (INMET) database through the Meteorological Database for Teaching and Research (in the abbreviation in Portuguese, BDMEP), to the period from January 2000 to December 2014, measured in the thirty three conventional meteorological stations and from January 2007 to December 2014 measured in the five automatic meteorological stations installed in the municipalities belonging to RHA, as observed in Figure 1. This period is justified by presenting more consistent values with fewer failures in the data set. However, these data went through a series of steps in order to be organized and analyzed, so the Multiple Imputation technique (Rubin, 1989; Junger and Leon, 2012) was used to fill any missing data in the observational meteorological series of according to the methodology adopted and described in Silva (2015). 
Table 1 - Meteorological variables, abbreviation and units.

\begin{tabular}{lcc}
\hline \hline \multicolumn{1}{c}{ Variable } & Unit & Abbreviation \\
\hline \hline -Average temperature* & ${ }^{\circ} \mathrm{C}$ & Tmed \\
Maximum temperature & ${ }^{\circ} \mathrm{C}$ & Tmax \\
Minimum temperature & ${ }^{\circ} \mathrm{C}$ & Tmin \\
Relative Humidity & $\%$ & $\mathrm{RH}$ \\
Insolation & $\mathrm{Hours}$ & $\mathrm{n}$ \\
Atmospheric pressure & $\mathrm{hPa}$ & $\mathrm{Pres}$ \\
Wind speed & $\mathrm{m} / \mathrm{s}$ & $\mathrm{u}_{2}$ \\
Precipitation & $\mathrm{mm}$ & $\mathrm{PPT}$ \\
Global Solar Radiation* & $\mathrm{W} / \mathrm{m}^{2}$ & $\mathrm{Rg}$ \\
\hline \hline
\end{tabular}

*Parameters estimated by empirical equations.

Normally, meteorological stations do not measure global solar radiation ( $\mathrm{Rad})$, because of the difficulty of measurement, together with the scarcity of instruments, such as pyranometers. Thus, the formula of Angstrom (1924), described by Ometto (1981), was proposed, which was proposed for Rad estimates as a function of hours of the sunshine our insolation (n). For the estimation of global solar radiation, we used Equation (2):

$$
\mathrm{R}_{\mathrm{g}}=\mathrm{R}_{\mathrm{o}}\left(\mathrm{a}+\mathrm{b} \cdot \frac{n}{N}\right)
$$

being, $\mathrm{Rg}$ the daily global solar radiation $\left(\mathrm{cal} . \mathrm{cm}^{-2}\right.$ $\mathrm{day}^{-1}$ ), at the ground level; Ro a Daily solar radiation received by a horizontal surface at the top of the atmosphere (cal. $\mathrm{cm}^{-2}$ day $^{-1}$ ); n number of hours of sunshine; $\mathrm{N}$ a Maximum sun exposure or photoperiod; $\mathrm{a}$ and $\mathrm{b}$ are empirical coefficients determined for each region. If $\mathrm{a}$ and $\mathrm{b}$ are not available for a given locality Sentelhas and Angelocci (2009) suggest the following approximation: $\mathrm{a}=0.29$ $* \cos \varphi(\varphi$ local latitude) and $b=0.52$ (constant). The values of solar radiation at the top of the atmosphere $(\mathrm{Ro})$ and the maximum insolation $(\mathrm{N})$ required in Equation (2) can be obtained without difficulty in Fernandes et al. (2010).

\subsection{Estimated ETo}

The estimates of ETo were calculated using the method developed by Penman-Monteith (Penman, 1948; Monteith, 1965) and later parameterized by FAO, Equation (3), (Allen et al., 1998). This method calculates the ETo of a reference crop using simplified assumptions of soil cover and vegetation growth without water constraints (for example, green grass with 0.12 meters and albedo of 0.23). The PM-FAO equation is given below:

$$
E T o=\frac{0,408 . \Delta\left(R_{n}-G\right)+\gamma\left(\frac{900 . u_{2}}{T_{\text {med }}+273}\right)\left(e_{s}-e_{a}\right)}{\Delta+\gamma \cdot\left(1+0,34 u_{2}\right)}
$$

in which: ETo is the reference evapotranspiration $\left(\mathrm{mm} \mathrm{day}^{-1}\right), \mathrm{Rn}$ is the net radiation at the crop surface $\left(\mathrm{MJ} \mathrm{m}^{-2} \mathrm{day}^{-1}\right), \mathrm{G}$ is the soil heat flux $\left(\mathrm{MJ} \mathrm{m}^{-2} \mathrm{day}^{-1}\right)$, Tmed is the average daily air temperature measured at 2 meters high $\left({ }^{\circ} \mathrm{C}\right), \mathrm{u} 2$ is the wind speed measured at 2 meters $\left(\mathrm{m} \mathrm{s}^{-1}\right)$, es is the saturation vapor pressure $(\mathrm{kPa}), \mathrm{e}$ is the current vapor pressure $(\mathrm{kPa}), \Delta$ is the slope of the vapor pressure curve $\left(\mathrm{kPa}^{\circ} \mathrm{C}^{-1}\right)$ and $\gamma$ is the psychrometric constant $\left(\mathrm{kPa}^{\circ} \mathrm{C}^{-1}\right)$.

The standardized equations and details for the calculation of all parameters of Equation (3) were performed as shown in Allen et al. (1998) and also in Silva (2015).

\subsection{Cluster Analysis}

After estimation of the monthly ETo for the localities inserted in the RHA, the homogeneous evapotranspiration regions were determined by means of the multivariate technique called Cluster Analysis (Mingoti, 2005). The Ward agglomerative hierarchical method (Bien and Tibshirani, 2011) was used, in which the measure of dissimilarity was the Euclidean distance that, according to Mimmack et al. (2001), is one of the measures indicated for regionalization of climatic data and corresponds to the geometric distance between two objects in the 
multidimensional plane, and can be obtained by the following equation:

$$
d_{x y}=\sqrt{\sum_{i=1}^{n}\left(X_{i}-Y_{i}\right)}
$$

where, $d_{x y}$ is the Euclidean distance; $X_{i}$ and $Y_{i}$ are elements to be compared, which in this research are the annual averages of ETo.

The Ward or Minimum Variance method was used to seek to join elements that make the groups formed as homogeneous as possible. This method searches for the least variance among the groupings, joining elements whose sum of squares between them is minimal or that the error of this sum is minimal (Hervada-Sala and Jarauta-Bragulat, 2004; Bien and Tibshirani, 2011).

The determination of the number of groups was performed using the technique of Analysis of the Behavior of the Fusion Level, and the groups formed visualized by the two-dimensional diagram called Dendrogram, detailed descriptions of these procedures can be found in Mingoti (2005). These groups were evaluated by the Silhouette Index (SI), elaborated by Rousseeuw (1987). The values of this index vary in the interval [-1,1]. Values near 1 indicate that the object is in the correct group. Values close to -1 indicate that the observation was probably allocated to an inadequate group and close to zero indicate that the object is close to the boundary between two groups and does not belong to one group or another.

Finally, ANOVA (Hoffmann, 2011) was applied in order to verify if the differences between the annual averages of ETo among the homogeneous sub-regions are statistically different. It is emphasized that ANOVA does not tell exactly which pairs of samples occur at significant differences. In this way, the Tukey HSD test, proposed by Tukey (1949) and described by Hoffmann (2011) and also by Pereira et al. (2014), was used as a complement. The test is also known as the Honestly Significant Difference (HSD) test. It consists in determining the confidence interval of the differences between the annual averages taken two to two of the sub regions, and if this interval does not include the value zero, the difference is significant. This procedure uses the amplitude of the t-student distribution and generally works with a significance level of 5\%.

\subsection{Sensitivity Analysis}

In order to determine the effect of a given variable in the ETo computation, using the PM-FAO equation in each homogeneous ETo region, the Sensitivity Analysis (SA) technique was used. An approach similar to that used by Gong et al. (2006) to obtain the monthly Sensitivity Coefficients (SC) for the meteorological variables: u2, Tmax, Tmin, RH and $\mathrm{Rg}$. The $\mathrm{SC}$ for each climatic variable was obtained by mathematically differentiating the equation or model under study. The relative nondimensionless SC of each variable was obtained by the following equation (McCuen, 1974):

$$
S C_{V i}=\frac{\partial E T o}{\partial V i} \cdot \frac{V i}{E T o}
$$

where, $\mathrm{SC}_{\mathrm{Vi}}$ is the coefficient of sensitivity and $\mathrm{Vi}$ is the $\mathrm{n}$ variable.

The partial derivatives, necessary for the determination of SC, were calculated analytically by means of $\mathrm{R}$ project software. A Monte Carlo simulation based on the definition of the coefficient of sensitivity $\left(\mathrm{SC}_{\mathrm{vi}}\right)$ was implemented for this purpose. In this work, the SC of the climatic variables were analyzed in the homestead sub region of the RHA. Basically, a positive/negative SC of a variable indicates that ETo will increase/decrease as the variable increases. The higher the coefficient of sensitivity, the greater the effect a given variable has on ETo. For example, an SC of 0.2 for a variable would mean, in this case, that a $10 \%$ increase in that variable, while all other variables are held constant, can increase ETo by $2 \%$.

\section{Results and discussion}

The homogeneous groups arranged in the RHA were identified using the Ward grouping method and as a measure of dissimilarity the Euclidean distance. The technique of Fusion Level Behavior Analysis was used to obtain an idea of the appropriate number of clusters, since this question of the number of groups is subjective, and is at the discretion of each researcher. Thus, the results of the clustering history (not shown) were obtained. Based on this technique, it was observed that from step 1 to 29 there was no significant loss of similarity or increase of distances. However, from stage 35 there 
was a more pronounced loss. In this way, it seems reasonable to define, as the final value of the number of groups, that corresponding to step 35, that is, number of groups equal to three.

In this case, the solution of three clusters can be very simple; it may not adequately represent differences in ETo patterns in the study region. A solution of seven groups (step 31) is still admirable and has the potential to offer more understanding of the different ETo patterns present in the data. Therefore, with these procedures and analyzes, the best number of groups formed for this dataset was seven. The corresponding Dendrogram is shown in Figure 2, where one observes the seven groups arranged and highlighted by colored rectangles.

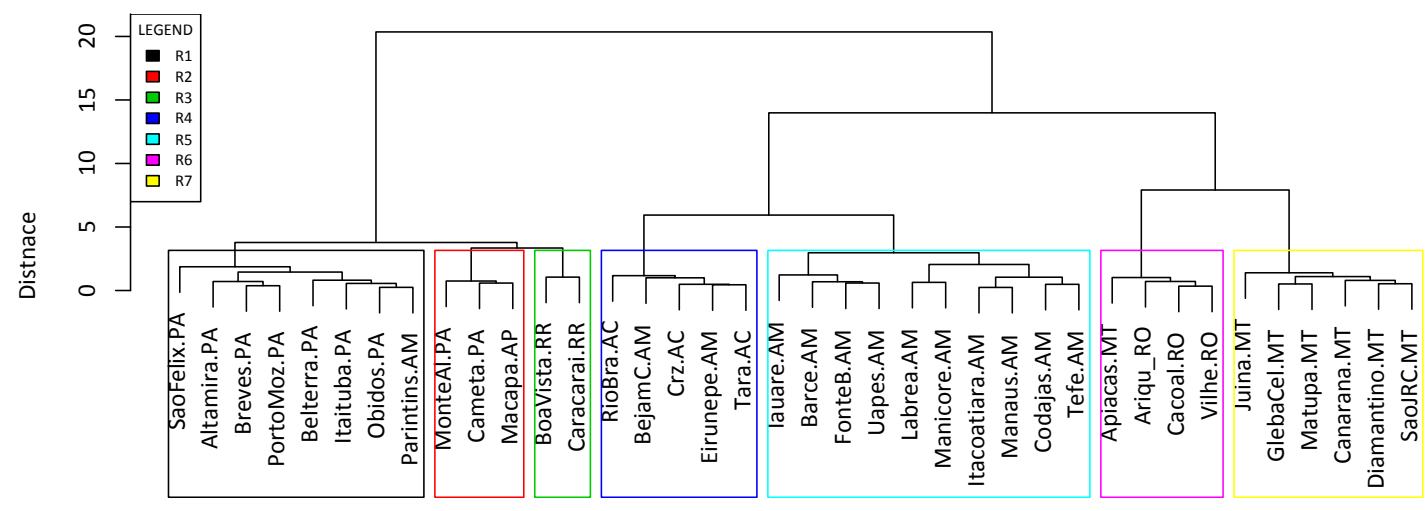

locations

Figure 2 - Dendrogram of the 38 localities of the RHA - Ward Method.

The next analyses will be on top of the formations of the seven homogeneous regions of ETo as indicated by the analysis of the previous paragraph as well as their evaluation through the Silhouette Index (SI). Figure 3a shows the spatial distribution of the seven homogeneous regions for the RHA, where each color corresponds to a homogeneous group. In Table 2, some descriptive statistics of ETo are summarized, such as mean, standard deviation and coefficient of variation. It should be noted that given the geographical proximity of the localities does not guarantee the climatic similarity between them, there have been cases in which the same homogeneous regions are observed in different areas of the RHA that may be associated with the spatial variability of the phenomenon.

It is seen from Figure $3 b$ that the formed groups showed positive SI. These indexes ranged from 0.26 to 0.62 with a mean of 0.39 , that is, the samples, on average, are allocated to apparently correct groups, with the exceptions of two samples being one of the $\mathrm{R} 1$ region and another of the $\mathrm{R} 2$ that have negative SIs that indicate that these samples are allocated to an inadequate group.

Figure $3 \mathrm{c}$ shows the average behavior of the monthly mean accumulated ETo for the study period. In general, the variability of ETo is very similar between homogeneous regions, with minimum and maximum occurring in the first and second semester, respectively. However, these homogeneous regions have different configurations due to the magnitude (maximum and minimum peaks) and intensity. As for example, the maxima of R2 and R7 occur on average in August. While in the others in October, with the exception of the R5 that presented two peaks of maximum, one in February and another in October.

Table 2 shows that the highest ETo value occurred at R6 followed by R5 and R7 with values ranging from $141.3 \pm 7.2,133.5 \pm 9.9$ to $122.3 \pm 5.7 \mathrm{~mm}$ month ${ }^{-1}$, respectively. These regions are located in the extreme north of the State of Roraima (R5), northeast of Pará (R6) and center-east of Mato Grosso (R7). Meanwhile, the lowest values occurred in the other sub regions, with $\mathrm{R} 2$ being the lowest in the state of Rondônia $\left(98.1 \pm 4.1 \mathrm{~mm} \mathrm{month}^{-1}\right)$. 
(a)

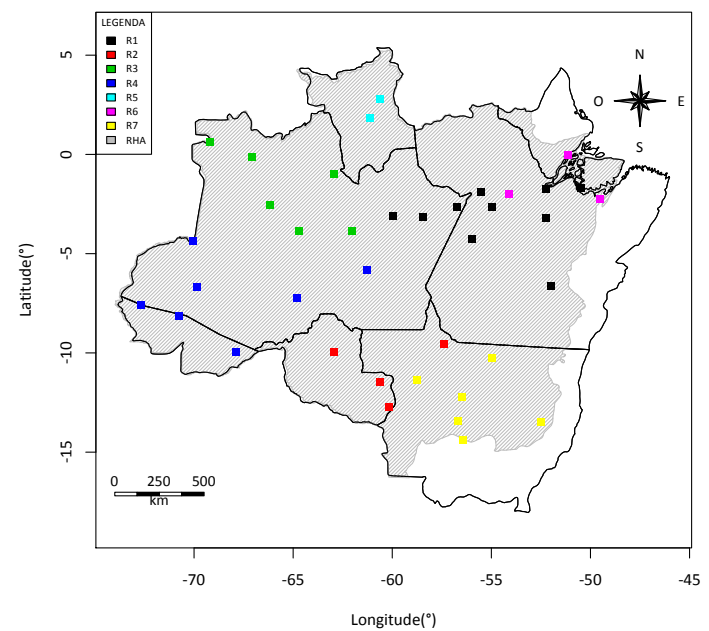

(b)

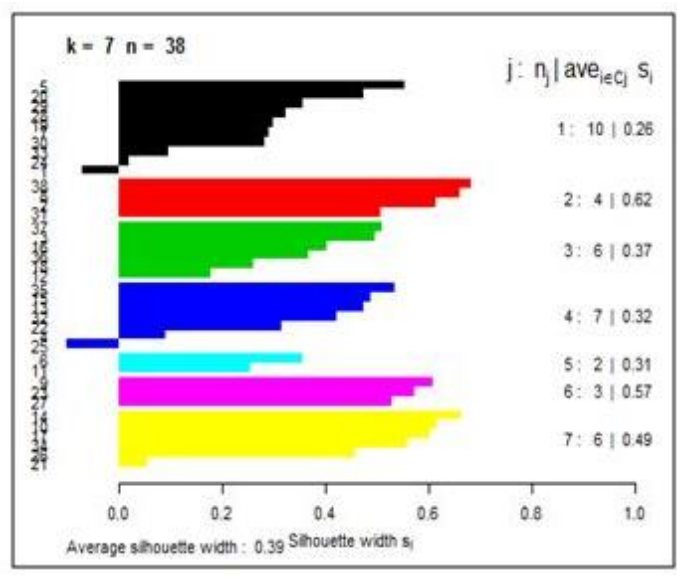

(c)

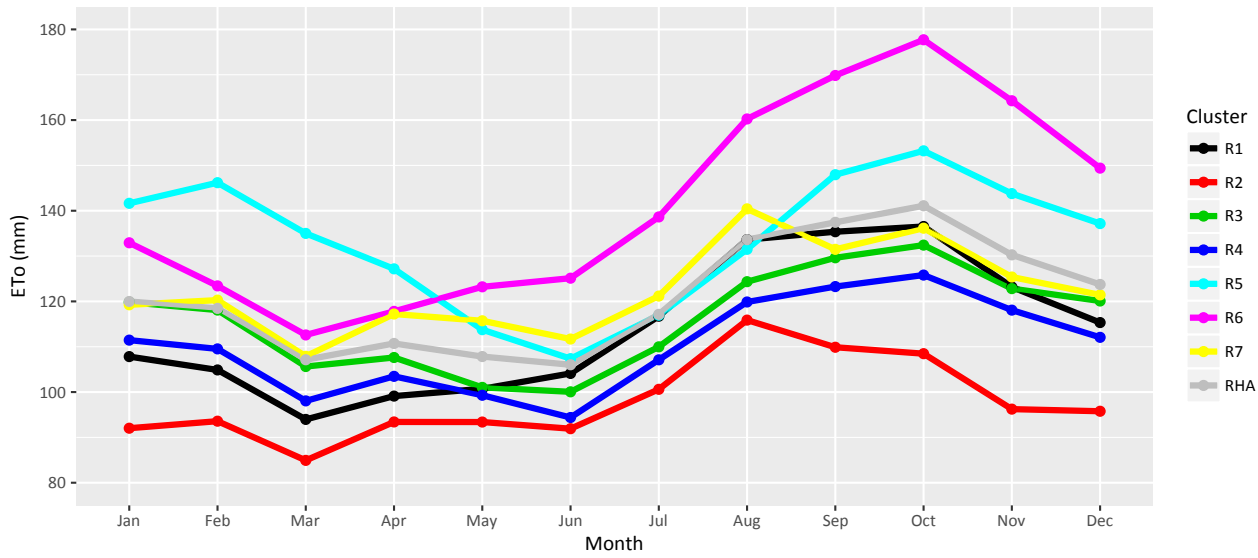

Figure 3 - Grouping analysis for RHA: (a) spatial distribution of homogeneous regions; (b) Silhouette Index (SI) graph and (c) Monthly average accumulated ETo belonging to regions (clusters) R1 to R7.

Table 2 - Descriptive statistics (Mean, Standard Deviation (SD) and Coefficient of Variation (CV)) of the ETo for the homogeneous regions of the AHR formed by the Grouping Analysis.

\begin{tabular}{lcccccccc}
\hline \multirow{2}{*}{ Statistics } & \multicolumn{7}{c}{ HOMOGENEOUS REGIONS OF ETo } \\
\cline { 2 - 9 } & R1 & R2 & R3 & R4 & R5 & R6 & R7 & RHA \\
\hline Average (mm month $\left.{ }^{-1}\right)$ & 114,3 & 98,1 & 115,9 & 110,2 & 133,5 & 141,3 & 122,3 & 119,4 \\
SD (mm) & 5,4 & 4,1 & 5,6 & 4,6 & 9,9 & 7,2 & 5,7 & 6,1 \\
CV (\%) & 4,7 & 4,4 & 4,8 & 4,1 & 7,4 & 5,1 & 4,7 & 5,1 \\
\hline \hline
\end{tabular}

The variability of the seasonal distribution of ETo observed in the seven homogeneous sub-regions is a natural phenomenon, resulting from a large number of physical, chemical and biological processes occurring in the various climatic components (atmosphere and terrestrial surface, among others). In the study region, these processes are induced by several local and remote factors. According to Trenberth and Hurrel (1994), local factors include the equatorial geographical location, the influence of the Tropical Atlantic, the existence of the Andes, as well as the Amazon forest. Among the remote factors are the Tropical Pacific, Subtropical Atlantic and the large-scale circulation patterns located in the Pacific and Atlantic.

The results found in this research corroborate with the literature obtained for the Amazon basin through data from reanalysis models (Marengo, 2005; Zeng, 1999; Fan and Miguez-Macho, 2010) and observational data (Rocha et al., 2004; Silva et al., 
2015). The mean of these observations $\left(\sim 3.8 \mathrm{~mm}\right.$ day $^{-}$ 1 or $114 \mathrm{~mm}$ month $\left.^{-1}\right)$ suggests that evapotranspiration derived from global models may be about $10 \%$ larger than observations (estimated or measured) ranging from 3.7 to $4.6 \mathrm{~mm} \mathrm{day}^{-1}$ (111 to $\left.138 \mathrm{~mm} \mathrm{month}^{-1}\right)$. However, they have similar seasonal patterns.

In order to better understand the seasonal cycle of ETo in the seven homogeneous sub-regions, the following analyzes were carried out around the seasonal cycles of rainfall (PPT), relative humidity $(\mathrm{RH})$, radiation balance $(\mathrm{Rn})$, mean temperature (Tmed) and wind speed (u2) which comprises the mean of the period from 2000 to 2014 for most meteorological stations (Figure 4).

For the rainfall data, it was divided into two figures (Figure $4 a$ and $b$ ). It is noted that the seasonal distribution of rainfall (PPT) over most regions is characterized by being unimodal. The rainy season in most regions occurs between November and March, with a peak in the austral summer, between December and February / March, and the dry season (less rainy) occurs from May to September. In the R5 region, the northernmost part of the RHA, there is a reversal of this phase in response to solar heating, and the rainy season occurs from May to September and the driest period, from November to March. For the UR (Figure 4c) it is observed that the monthly average accompanies the seasonal distribution of the rainy season and the dry of the PPT of the respective homogeneous regions. Tmed has similar seasonal behavior in most regions, with winter minimums (JJA) and spring maximums (OSN). In the R2, R4 and $\mathrm{R} 7$ regions, the greatest thermal amplitudes ( $2^{\circ} \mathrm{C}$ ) were verified when compared with the other regions. The strongest seasonal pattern in these regions is explained by the incursions of polar (dry and cold) air masses from the south of Brazil, locally known as "friagem", frequent in the autumn and austral winter months (Marengo et al., 1997). However, the higher temperatures are observed in regions $\mathrm{R} 1, \mathrm{R} 5$ and $\mathrm{R} 6$, due to their geographic location to the north, which receive more solar energy during the year (Salati and Marques, 1984).
As for wind velocity (u2), it can be seen from Figure 4e that for the R5 and R6 regions the seasonal pattern was more defined and with larger amplitudes, presenting on average lower values between autumn and winter and higher in spring with average between 1.5 and $2.5 \mathrm{~m} \mathrm{~s}^{-1}$. For the other regions, there are few variations in the annual cycle, but the values are relatively smaller in the first semester and higher in the second with annual averages around $1.0 \mathrm{~m} \mathrm{~s}^{-1}$. In Figure $4 \mathrm{f}$, it is observed that between the regions there is a similarity in the annual cycle of the radiation balance $(\mathrm{Rn})$, but they present differences in their amplitudes and in the occurrence of maxima and minima. For example, the R1, R3, R4, R5 and R6 regions occur in September, while in R2 and R7 in October, and the minimum values generally occur between May and June. This seasonal temporal variability of Rn over homogeneous regions is mostly controlled by the nebulosity associated with intense local convection (Horel et al., 1989). The cloud is the most variable component of the climate system and plays an important role in the determination of the climate, and act as both solar radiation reflectors and terrestrial radiation absorbers, implying energy balance and consequently in the Rn (Liebmann et al., 1998).

These patterns and intensities of the meteorological variables observed in the seven homogeneous subregions of the Brazilian Amazon are consistent with studies reported in the literature (Marengo et al., 2004; Marengo, 2009). They demonstrate that the different seasonal patterns in the northern (northeast/northwest) and southern (southwest/southeast) Amazon are due to the spatial / temporal variability of the meteorological systems operating in the region. These are associated mainly with convective and moisture transport mechanisms from evaporation in the Atlantic Ocean, associated with the Intertropical Convergence Zone (ITCZ) and evapotranspiration in the Amazon rainforest, as well as synoptic scale systems such as the South Atlantic Convergence Zone (SACZ), which over time, their influences decrease gradually in these regions (Nobre et al., 1991; Duarte, 2006; Villar et al., 2009). 


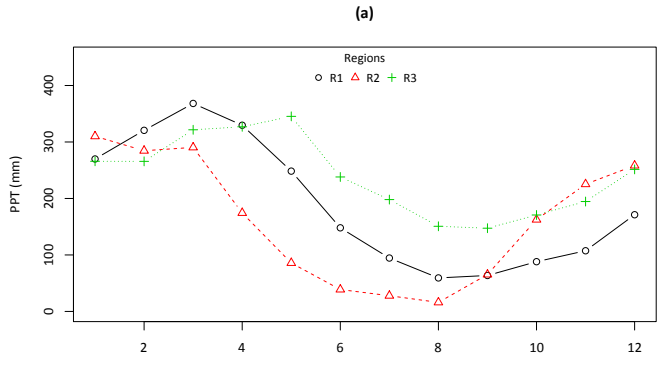

(c)
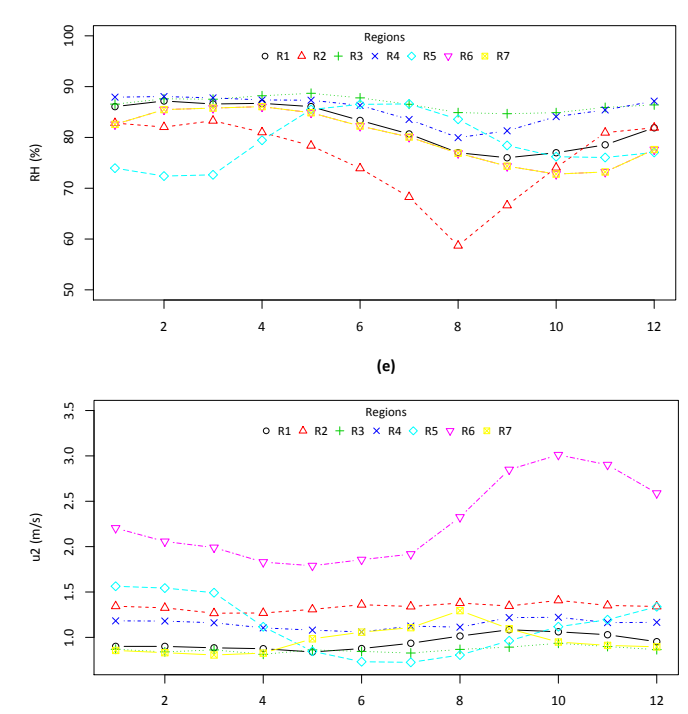

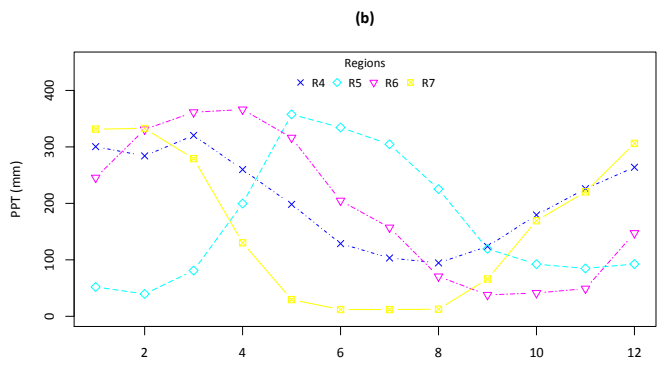

(e)
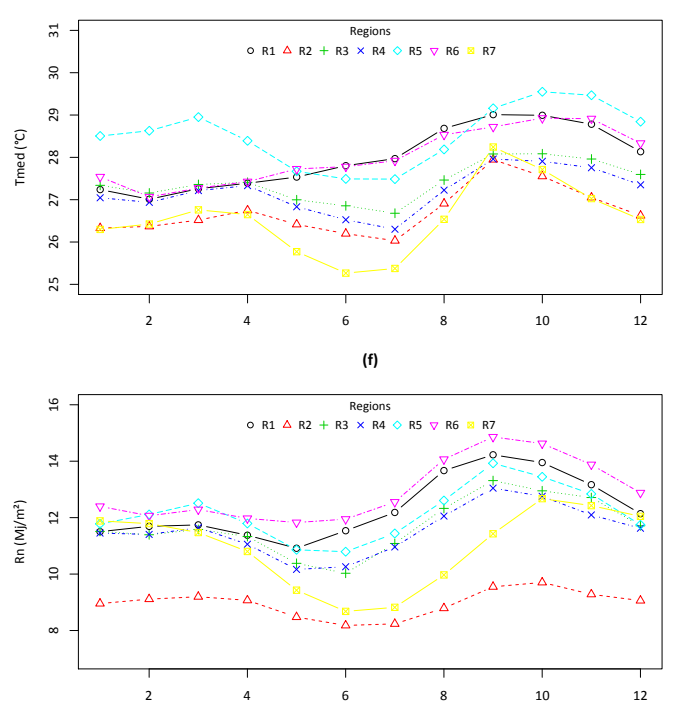

Figure 4 - Average monthly variability of climatic variables: rainfall (a and b), relative humidity (c), average temperature (d), wind velocity (e) and radiation balance (f) for the seven homogeneous ETo regions of Amazonia Brazilian.

Figure 5 shows the Sensitivity Coefficients (SC) for the variables balance of radiation $(\mathrm{Rn})$, maximum and minimum temperatures (Tmax and Tmin), relative humidity of the air (RH) and wind speed (u2), measured at 2 meters for each of the seven sub regions over the annual cycle. Although no cut-off value other than SC has been defined, the rather arbitrary value of 0.05 is often accepted in the literature for this type of analysis and for distinguishing important parameters from nonimportant ones in more complex models.

Thus, in general, it can be observed that the variables that contribute the most, that is, with the greatest influence in obtaining ETo in the study region were $\mathrm{Rn}$ and $\mathrm{u} 2$, with mean $\mathrm{SC}$ of 0.28 and 0.15 , respectively . These SC present an expressive behavior for the entire annual cycle, indicating that in this experimental scenario, this subset of variables are the ones that most affect the response variable of the parameterized model of Penman-Monteith-FAO. Where a variation of $10 \%$ of these variables, while the others remain constant, can increase ETo by $2.8 \%$ and $1.5 \%$, respectively. The temperatures (Tmax and
Tmin) in conjunction with the UR presented minimum values of CS $(<0.02)$ indicating that these variables have low or no influence on the prediction of ETo, except for Tmax, which in R2 and R7 presented CS of 0.06 in the month of August and of 0.07 in the R6 from September to November. However, the CS of the UR presented negative values for all the months of the year, that is, the increase of this variable reduces ETo, thus becoming a limiting factor, even if subtly.

It is observed that in R1, R3, R4, R5 and R6 (Figure 5a, 5c, 5d, 5e and 5f) Rn is the parameter that has the greatest influence on ETo, being predominant in all months, followed by $\mathrm{u} 2$ that showed the greatest influence in the second semester, agreeing with the seasonal pattern of these variables in the respective regions (Figures $4 \mathrm{e}$ and $4 \mathrm{f}$ ), but remaining below Rn, with the exception of R5 and R6 that in October to December are equivalent. For the R2 and $\mathrm{R} 7$ regions (Figure $5 \mathrm{~b}$ and $5 \mathrm{~g}$, respectively), we observe a strong seasonal behavior of the $\mathrm{SC}$ for the parameters $\mathrm{Rn}$ and $\mathrm{u} 2$, where in the period from November to April the parameter $\mathrm{Rn}$ is the most 
influential variable followed by $\mathrm{u} 2$. From June to September, $\mathrm{u} 2$ is the most influential variable in ETo computing, agreeing on average with the seasonal pattern of ETo (Figure 4e).
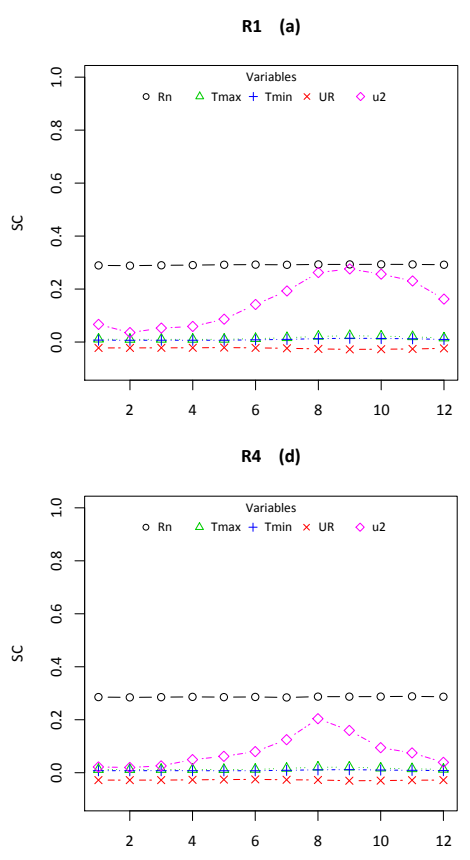

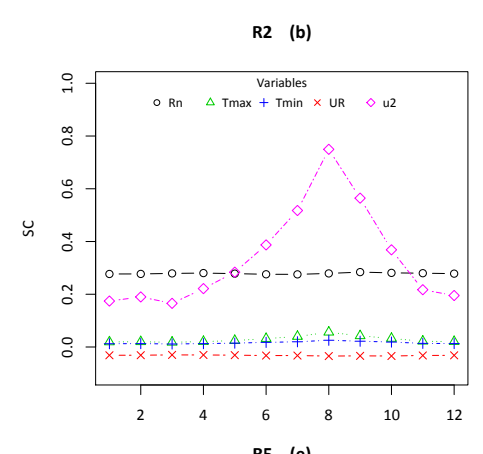

R5 (e)

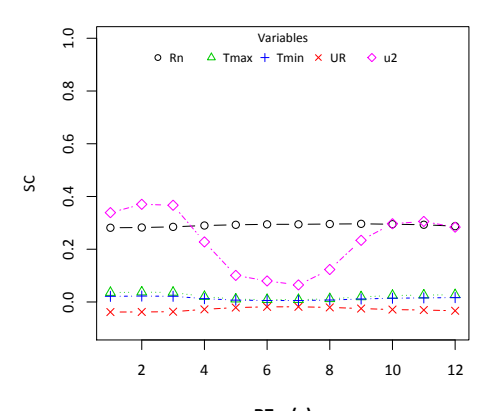

R7 (g)

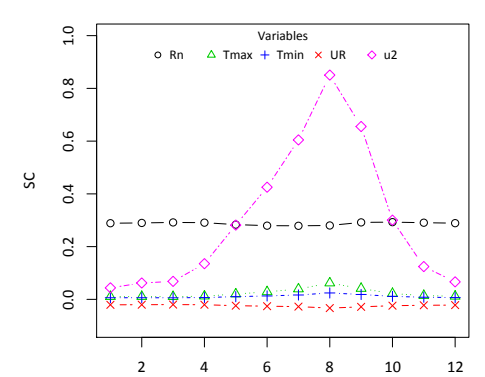

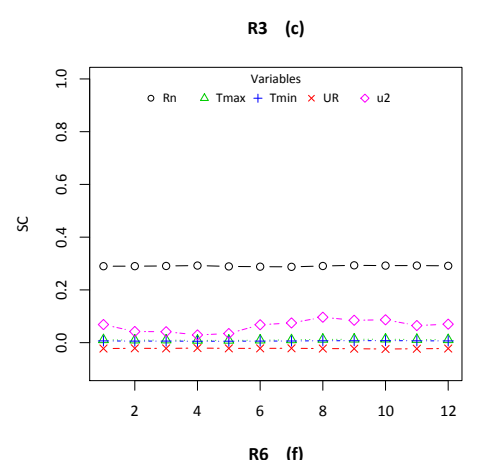

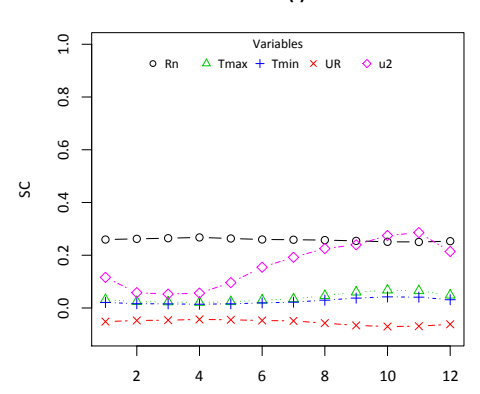

Figure 5 - Monthly average of the sensitivity coefficients for maximum temperature (Tmax), minimum temperature (Tmin), relative humidity $(\mathrm{RH})$, wind speed $(\mathrm{u} 2)$ and radiation balance $(\mathrm{Rn})$ for the seven sub regions of the Brazilian Amazon : (a) R1, (b) R2, (c) R3, (d) R4, (e) R5, (f) R6 and (g) R7.

Thus, for the annual cycle, it was observed that the variables that contribute most to the computation of the ETo using the standardized Penman-Monteith-FAO method in the RHA were the balance of radiation and wind speed. For R1, R3, R4 and $\mathrm{R} 6, \mathrm{Rn}$ is the variable that contributes most during the whole annual cycle, whereas for drier regions with lower precipitation values such as $\mathrm{R} 2$ and R7, the wind speed is the most influential variable, but it is restricted in the less rainy months. This situation can be explained due to the great morphoclimatic variability (climate, orography and vegetation) of the region of study associated with its great territorial extension. According to Santos et al. (2015), in the Amazon, allow the development and performance of different climate systems, such as ITCZ and SACZ, among others, such as Lines of Instability and incursion of Frontal Systems ("friagens") that contribute significantly to the temporal space variability of these variables.

Similar results were found by Irmak et al. (2006), who analyzed the effects of climatic elements on ETo estimated by the PM-FAO equation in different regions of the United States of America with different climatic characteristics and also by Debnath et al. (2015) and Bakhtiari and Liaghat (2011) in India and Iran, respectively. These authors verified that solar radiation, which is used for the calculation of $\mathrm{Rn}$, was the most influential parameter in humid places, whereas in drier places (arid and semi-arid) it was the wind speed in the months of less convective activity in those regions, that is, with less cloudiness (less rainy period). In Brazil Lemos Filho et al. (2010) verified that solar radiation and wind speed were the most sensitive variables in the centralwest region of Minas Gerais. However, Silva et al. 
(2011) found that in the northern region of the state of Paraíba (northeastern Brazil) the balance of radiation followed by relative humidity were the most sensitive variables in the ETo computation. However, Gong et al. (2006) found that the most sensitive variable in this equation in their area of study (China) was the relative humidity of the air followed by short-wave radiation and air temperature; the wind speed presented the lowest values of sensitivity coefficients while in Greece, Paparrizos et al. (2016) found as the most sensitive variable the balance of radiation followed by maximum and minimum temperatures. These were explained mainly by the great spatial variability of these regions.

Retrieving the analyzes of the seasonal variability of ETo in the seven sub regions of the Brazilian Amazon (Figure 3c) together with Figure 5. It can be inferred that the temporal variability (maximum and minimum) of the ETo in the sub regions are explained by the parameters $\mathrm{Rn}$ and $\mathrm{u} 2$, since these parameters were generally more sensitive throughout the year in these sub regions (Figure 5). For the R1, R3, R4, R5, and R6 regions, the minimum and maximum of the ETo are coincident with the seasonality of the parameter Rn, which presents minimum values in autumn while the maximums occur simultaneously in the spring. However, for the R2 and R7 regions the minimum values of ETo oscillated between autumn and winter, which can be influenced by either $\mathrm{Rn}$ or $\mathrm{u} 2$, while the maximums coincide with the maximum values of $\mathrm{u} 2$ occurring in august.

Table 3 shows the ANOVA results. It was verified by means of $p$-value at $1 \%$ of significance that the differences between the annual averages were highly significant. This suggests that there is at least one significant difference between the pairs of ETo samples.

Table 3 - The result of application of the ANOVA technique for the annual averages of ETo for the seven ETo homogeneous regions of the RHA: R1, R2, R3, R4, R5, R6 and R7.

\begin{tabular}{lccccc}
\hline \hline Source of Variation & $\begin{array}{c}\text { Degrees of } \\
\text { freedom }\end{array}$ & Quadratic sum & Middle square & F $_{\text {calc }}$ & Value-p \\
\hline Between the regions & 6 & 14367 & 2394,5 & 332 & $* * *$ \\
Within regions & 90 & 649 & 7,21 & - & - \\
Total & 96 & 15016 & - & - \\
\hline \hline
\end{tabular}

**: level of significance of $5 \% ; * * *$ : level of significance of $1 \%$.

In order to verify exactly which pairs of samples (regions) occurred to the significant differences, the Tukey-HSD test was used (Figure 6), where the values of the differences of the average values of the homogeneous regions are found in the axis of the abscissa, in the axis of the ordered, the respective pairs of samples taken every two (R1-R2, ... and so on). The decision criterion was that if the confidence interval, created around the meanings of the pairs of samples, contains the value zero, we do not reject the hypothesis of equality between the means, otherwise, the null hypothesis is rejected.

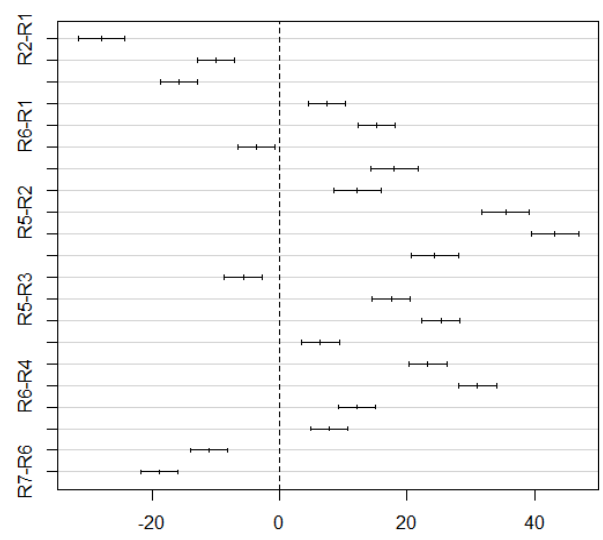

Figure 6 - Confidence interval of $95 \%$ between the differences of the means of the ETo in the annual scale between the sample pairs of each homogeneous sub-region. 
Thus, for the annual scale, it was observed that all sample pairs presented statistical difference at $5 \%$ significance (Figure 6). This situation can be explained due to the great territorial extension of the study region where several meteorological systems act in a heterogeneous way during the annual cycle modulating the meteorological variables that condition the ETo as well as the conditions of relief and vegetation implying in their average values.

In order to guarantee the efficacy and assumptions of normality, homoscedasticity (constant variance) and independence of the ANOVA model, we performed the analysis of the residues by means of the statistical tests of normality, homoscedasticity and independence for the variable of interest by means of the tests of Shapiro-Wilk, Cochran and Durbin-Watson, respectively, described in Royston (1982). The results of the tests, not shown, guaranteed the ANOVA assumptions at 5\% significance, as can also be verified by Figure 7 , where there is no evidence of a breakdown of these assumptions.

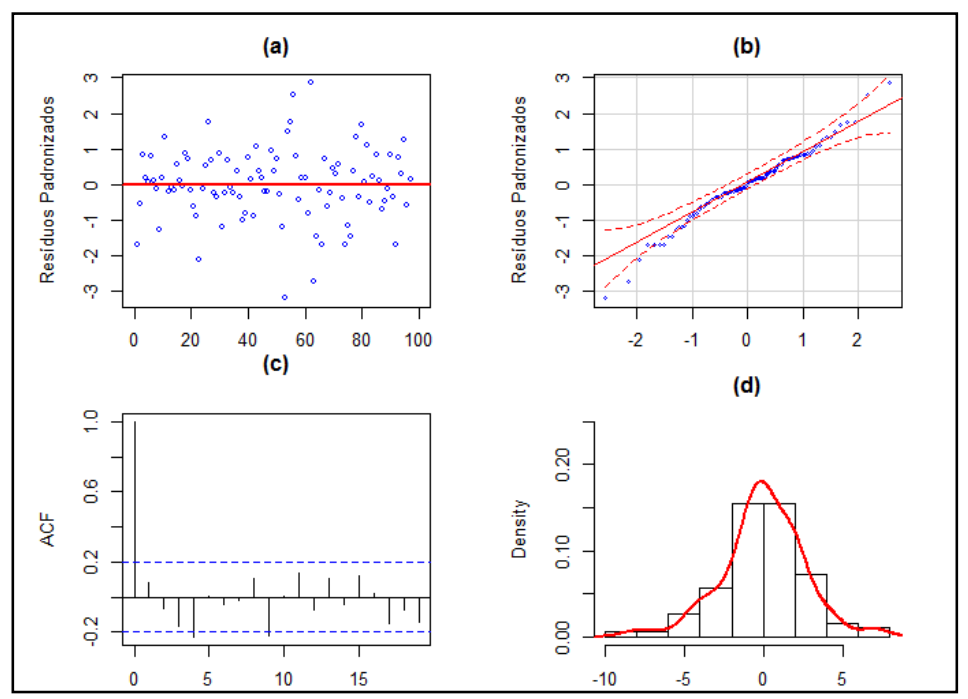

Figure 7 - Graph of the residuals of the ANOVA model for variance (a), normality (b and d) and independence (c).

\section{Conclusions}

The results suggest that three homogeneous sub-regions are sufficient to divide the Brazilian Amazon into different ETo patterns, but in a more detailed analysis, it was shown that the ideal is to use seven sub regions, which were separated considering the intensity and the seasonal pattern of ETo. All the sub-regions formed by the hierarchical agglomerative Ward method presented statistical difference at $5 \%$ of significance. These are consistent with the behavior of the main meteorological variables that condition the ETo, which by the Sensitivity Coefficient indicated that the Radiation Balance and wind speed are the most sensitive variables in the estimation of ETo by the standard Penman-Monteith-FAO method.

These results demonstrate that, in general, precise measurements of sunshine and / or global solar radiation should be emphasized, since the precise estimate of $\mathrm{Rn}$ is directly associated with the measurement of these variables as well as the wind speed that was shown to be the second the most influential variable in ETo computation.
Thus, the results of this study can serve to aid in the analysis and the meteorological forecasts and the validation of the annual cycle of climate models. In addition, it may also be useful to evaluate the response of the Penman-Monteith-FAO standardized equation in different climatic conditions.

\section{Acknowledgments}

To the Federal University of Rio Grande do Norte (UFRN) for the financial support and encouragement of research through the Postgraduate Program in Climate Science (Programa de PósGraduação em Ciências Climáticas - PPGCC), and to the Coordination for the Improvement of Higher Education Personnel (Coordernação de Aperfeiçoamento de Pessoal de Ensino Superior CAPES).

\section{References}

Alencar, L.P., Sediyama, G.C., Wanderley, H.S., Almeida, T.S., Delgado, R.C., Vieira, G.H.S., 2012. Evolução temporal da evapotranspiração de 
referência e sua sensibilidade aos principais elementos climáticos na cidade de Uberaba - MG. Revista Brasileira de Ciências Agrárias 7, 159166.

Allen, R.G., Pereira, L.S., Raes, D., Smith, M., 1998. Crop evapotranspiration: guidelines for computing crop water requirements. FAO, Rome.(Irrigation and Dranaige Paper, 56).

Ambas, V.Th., Baltas, E., 2012. Sensitivity analysis of different evapotranspiration methods using a new sensitivity coefficient. Global NEST Journal 14, 335-343.

ANA. Agência Nacional de Águas, 2016. Região Hidrográfica Amazônica. Disponível: http://www2.ana.gov.br/Paginas/portais/bacias/am azonica.aspx. Acesso: 24 nov. 2016.

Bakhtiari, B., Liaghat, A.M., 2011. Seasonal Sensitivity Analysis for Climatic Variables of ASCE-Penman-Monteith Model in a Semi-arid Climate. Journal of Agricultural Science and Technology 13, 1135-1145.

Bien, J., Tibshirani, R., 2011. Hierarchical clustering with prototypes via minimax linkage. Journal of the American Statistical Association 106, 10751084.

Carvalho, L.G., Rios, G.F.A., Miranda, W. L., Neto, P.C., 2011. Evapotranspiração de referência: uma abordagem atual de diferentes métodos de estimativas. Pesquisa Agropecuária Tropical 41, 456-465.

Debnath, D.S., Adamala, S., Raghuwanshi, N.S., 2015. Sensitivity Analysis of FAO-56 PenmanMonteith Method for Different Agro-ecological Regions of India. Environmental Processes 2, 689-704.

Duarte, A.F., 2006. Aspectos da climatologia do Acre, Brasil, com base no intervalo $1971-2000$. Revista Brasileira de Meteorologia 21, 308-317.

Fan, Y., Miguez-Macho, G., 2010. Potential groundwater contribution to Amazon evapotranspiration. Hydrology Earth System Sciences 14, 2039-2056.

Fernandes, D.S., Heinemann, A.B., Amorim, A.O., 2010. Evapotranspiração - Uma Revisão sobre os Métodos Empíricos. Embrapa Arroz e Feijão, Santo Antônio de Goiás. (Documentos, 263).

Frey, H.C., Patil, S.R., 2002. Identification and review of sensitivity analysis methods. Risk Analysis 22, 553-578.

Gavilán, P., Berengena , J., Allen, R.G., 2007. Measuring versus estimating net radiation and soil heat flux: Impact on Penman-Monteith reference ET estimates in semiarid regions. Agricultural Water Management 89, 275-286.

Gong, L., XU, C-yu, Chen, D., Halldin, S., Chen, Y.D., 2006. Sensitivity of the Penman-Monteith reference evapotranspiration to key climatic variables in the Changiiang (Yangtze River) basin. Journal of Hydrology 329, 620-629.

Hervada-Sala, C., Jarauta-Bragulat, E., 2004. A program to perform Ward's clustering method on several regionalized variables. Computers \& Geosciences 30, 881-886.

Hoffmann, R., 2011. Estatística para Economistas. 4. ed. rev. e ampl., Cengage Learning, São Paulo.

Horel, J.D., Hahmann, A.N., Geisler, J.E., 1989. An investigation of the annual cycle of convective activity over the tropical Americas. Journal of Climate 2, 1388-1403.

IBGE. Instituto Brasileiro de Geografia e Estatística, 2010. Disponível: http://ibge.gov.br/. Acesso: 15 fev. 2017.

Irmak, S., Payero, J.O., Martin, D.L., Irmak, A., Howell, T.A., 2006. Sensitivity Analyses and Sensitivity Coefficients of Standardized Daily ASCE-Penman-Monteith Equation. Journal of Irrigation and Drainage Engineerin 132, 564-578.

Itenfisu, D., Elliot, R.L., Allen, R.G., Walter, I.A., 2003. Comparison of reference evapotranspiration calculations as part of the ASCE standardization effort. Journal of Irrigation and Drainage Engineering 129, 440-448.

Jovanovic, N., Israel, S., 2012. Critical review of methods for the estimation of actual evapotranspiration in hydrological models, in: Irmak, A. (Ed.) Evapotranspiration - Remote Sensing and Modelling. Intech, Rijeka, Croatia.

Junger, W., Leon, A.P., 2012. MTSDI: Multivariate time series data imputation. $\mathrm{R}$ package 0.3.3.

Kannan, N., White, S.M., Worrall, F., Whelan, M.J., 2007. Sensitivity analysis and identification of the best evapotranspiration and runoff options for hydrological modeling in SWAT-2000. Journal Hydrology 332, 456-466.

Lemos Filho, L.C.A., Carvalho, L.G., Evangelista, A.W.P., Alves Júnior, J., 2010. Análise espacial da influência dos elementos meteorológicos sobre a evapotranspiração de referência em Minas Gerais. Revista Brasileira de Engenharia Agrícola e Ambiental 14, 1294-1303.

Liebmann, S.L., Marengo, J.A., Glick, J.D., Kousky, R.E., Wainer, I.C., Massambani, O., 1998. Comparison of Long wave radiation, divergence and rainfall in the Brazilian Amazon basin. Journal of Climate 7, 2898-2909.

Marengo, J.A., 2009. Mudanças climáticas, condições meteorológicas extremas e eventos climáticos no Brasil, in: Mudança Climáticas e Eventos Extremos no Brasil. Fundação Brasileira para o Desenvolvimento Sustentável - FBDS, Rio de Janeiro, pp. 4-18.

Marengo, J.A., 2005. The characteristics and variability of the atmospheric water balance in the 
Amazon basin: Spatial and temporal variability. Climate Dynamics 24, 11-22.

Marengo, J.A., Fisch, G., Morales, C., Vendrame, I., Dias, P.C., 2004. Diurnal variability of rainfall in Southwest Amazonia during the LBA-TRMM field campaign of the Austral summer of 1999. Acta Amazonica 34, 593-603.

Marengo, J.A., Nobre, C.A., Culf, A.D., 1997. Climatic impacts of "Friagens" in forest and deforest areas of the Amazon basin. Journal Application Meteorological 36, 1553-1566.

Marengo, J.A., Nobre, A.C., 2009. Clima da Região Amazônica, in: Cavalcante, I.F.A. et al. (Org.), Tempo e Clima no Brasil. Oficina de Texto, São Paulo, pp. 200-207.

Mimmack, G.M., MASON, S.J., GALPIN, J.S., 2001. Choice of distance matrices in cluster analysis: defining regions. Journal of Climate 14, 2790-2797.

Mingoti, S.A., 2005. Análise de dados através de métodos de estatística multivariada: uma abordagem aplicada. Ed. UFMG, Belo Horizonte.

$\mathrm{Mu}$, Q., Heinsch, F.A., Zhao, M., Running, S.W., 2007. Development of a global evapotranspiration algorithm based on MODIS and global meteorology data. Remote Sensing of Environment 111, 519-536.

Nobre, C.A., Sellers, P.J., Shukla, J., 1991. Amazonian Deforestation and Regional Climate Change. Journal of Climate 4, 957-988.

Ometto, J.C., 1981. Bioclimatologia vegetal, 1. ed. Agronômica Ceres, São Paulo.

Paparrizos, S., Maris, F., Matzarakis, A., 2016. Sensitivity analysis and comparison of various potential evapotranspiration formulae for selected Greek areas with different climate conditions. Theoretical and Applied Climatology 128, 745159.

Pereira, M.A.F., Kobiyama, M., Castro, M.R., 2014. Análise de Variâncias Pluviométricas na Bacia Hidrográfica do Rio Taboão - RS. Revista Brasileira de Meteorologia 29, 409-419.

Rocha, H.R., Goulden, M.L., Miller, S.D., Menton, M.C., Pinto, L.D.V.O., Freitas, H.C., Figueira, A.M. S., 2004. Seasonality Of Water And Heat Fluxes Over A Tropical Forest In Eastern Amazonia. Ecological Applications 14, S22-S32.

Rousseeuw, P.J., 1987. Silhouettes: a graphical aid to the interpretation and validation of cluster analysis. Journal of Computational and Applied Mathematics 20, 53-65.

Royston, P., 1982. An extension of Shapiro and Wilk's W test for normality to large samples. Applied Statistics 31, 115-124.
Rubin, D.B., 1989. Multiple imputation after 18+ years. JASA 91, 473-489.

Salati, E., Marques, J., 1984. Climatology of the Amazon region, in The Amazon. Harald Sioli. Springer Netherlands, Boston, pp. 85-126.

Saltelli, A., Ratto, M., Andres, T., Campolongo, F., Cariboni, J., Gatelli, D., Saisana, M., Tarantola, S., 2008. Global Sensitivity Analysis. The Primer. Wiley \& Sons, Chi-chester.

Saltelli, A., Tarantola, A., Campolongo, F., Ratto, M., 2004. Sensitivity Analysis in Practice: a guide to assessing scientific models. John Wiley \& Sons, Nova Jersey.

Santos, E.B., Lucio, P.S., Silva, C.M.S., 2015. Precipitation regionalization of the Brazilian Amazon. Atmospheric Science Letters 16, 195192.

Sentelhas, P.C., Angelocci, L.R., 2009. Evapotranspiração - definições e conceitos. LCE 306 - Meteorologia Agrícola, ESALQ/USP, Piracicaba.

Silva, B.K.N., Silva, V.P.R.da, Azevedo, P.V., Farias, C.H.A., 2011. Análise de sensibilidade dos métodos de estimativa da evapotranspiração de referência e razão de Bowen em cultura da canade-açúcar. Revista Brasileira de Engenharia Agrícola e Ambiental 15, 1046-1053.

Silva, H.J.F., 2015. Análise de tendência e caracterização sazonal e interanual da evapotranspiração de referência para o sudoeste da Amazônia brasileira: Acre, Brasil. Dissertação (Mestrado). Natal, UFRN.

Silva, H.J.F., Lucio, P.S., Brown, I.F., 2015. Análise mensal, sazonal e interanual da evapotranspiração de referência para o sudoeste da Amazônia, Acre, Brasil. Revista Brasileira de Geografia Física 8, 1711-1729.

Trenberth, K.E., Hurrel, J.W., 1994. Decadal atmosphere-ocean variations in the Pacific. Climate Dynamics 9, 303-319.

Villar, J.C.E., Ronchail, J., Guyot, J.L., Cochonneau, G., Naziano, F., Lavado, W., Oliveira, E.de, Pombosag, R., Vauchelh, P., 2009. Spatiotemporal rainfall variability in the Amazon basin countries (Brazil, Peru, Bolivia, Colombia, and Ecuador). International Journal of Climatology 29, 1574-1594.

Yang, J., 2011. Convergence and uncertainty analyses in Monte-Carlo based sensitivity analysis. Environmental Modelling \& Software 26, 444-457.

Zeng, N., 1999. Seasonal cycle and interannual variability in the Amazon hydrologic cycle. Journal Geophysics Research 104, 9097-9106. 